\title{
EXTENSÃO UNIVERSITÁRIA:
}

\section{um conceito em construção}

Wagner Pires da Silva ${ }^{1}$

\section{RESUMO}

A s ações de Extensão fazem parte do tripé universitário junto ao ensino e à Pesquisa. No entanto, ao longo do tempo, tanto a sua atuação, quanto o próprio conceito de Extensão foi sendo construído e modificado. Este trabalho desenvolve o histórico da conceituação e as discussões que embasam as atividades extensionistas na atualidade. Indispensável na relação com a sociedade extra-muros da Universidade, a Extensão se apresenta como uma ferramenta importante para a democratização da Universidade e dos saberes que nela são produzidos. Demonstrando como o tema tem sido aplicado na prática, a pesquisa apresenta as atividades do programa Viés Cariri, desenvolvido na Universidade Federal do Cariri, que busca realizar, a partir do contato entre os saberes acadêmico e popular, uma síntese capaz de dar respostas às demandas da sociedade. O artigo aponta que a Extensão Universitária, como demonstra a sua historicidade, é um conceito em construção, modificando-se através do tempo em resposta às demandas que a sociedade faz às universidades.

Palavras-chave: Conceito de Extensão. Relação Universidade-Sociedade. Ações de extensão.

\section{EXTENSIÓN UNIVERSITARIA: un concepto en construcción}

\section{RESUMEN}

as acciones de extensión forman parte del trípode universitario junto con la docencia y la investigación. Sin embargo, con el tiempo, tanto su rendimiento como el concepto de Extensión en sí se han construido y modificado. Este trabajo desarrolla la historia del concepto y las discusiones que apoyan las actividades de extensión en la actualidad. Indispensable en la relación con los muros exteriores de la universidad, Extensión se presenta como una herramienta importante para la democratización de la Universidad y el conocimiento que se produce en ella. Demostrando cómo se ha aplicado el tema en la práctica, el trabajo presenta las actividades del programa Viés Cariri, desarrollado en la Universidad Federal de Cariri, que busca realizar, a partir del contacto entre el saber académico y el popular, una síntesis capaz de dar respuesta a las demandas de la sociedad. El artículo señala que Extensión Universitaria, como lo demuestra su historicidad, es un concepto en construcción, cambiando con el tiempo en respuesta a las demandas que la sociedad hace a las universidades.

Palabras clave: Concepto de Extensión. Relación Universidad-Sociedad. Acciones de Extensión.

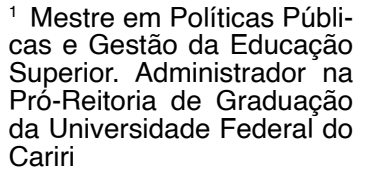
Cariri 


\section{UNIVERSITY EXTENSION: a concept under}

\section{construction}

\section{ABSTRACT}

Hxtension actions are part of the university tripod together with teaching and Eresearch. However, over time, both its performance and the concept of Extension itself has been built and modified. This work develops the history of the concept and the discussions that support extension activities today. Indispensable in the relationship with the university's outside walls, Extension presents itself as an important tool for the democratization of the University and the knowledge that is produced in it. Demonstrating how the theme has been applied in practice, the work presents the activities of the Viés Cariri program, developed at the Federal University of Cariri, which seeks to carry out, from the contact between academic and popular knowledge, a synthesis capable of responding to society's demands. The article points out that University Extension, as demonstrated by its historicity, is a concept under construction, changing over time in response to the demands that society makes to universities.

Keywords: Extension Concept. University-Society Relationship. Extension actions.

\section{INTRODUÇÃO}

Dara muitas pessoas, "extensão" diz respeito apenas aos cursos de curta duração ofertados pela universidade. Mas longe do senso comum, a Extensão é bem mais que isso. A Lei de Diretrizes e Bases da Educação estabelece que a promoção da extensão é uma das finalidades da educação superior, devendo ser "aberta à participação da população, visando a difusão das conquistas e benefícios resultantes da criação cultural e da pesquisa científica e tecnológica geradas na instituição" (BRASIL, I996).

A Extensão pode englobar um grande número de ações na universidade e, para entender o escopo dessas ações e o seu sentido de ser, faz-se necessário entender o que é a extensão, quais as suas finalidades e a sua importância para a universidade. A Constituição Federal de 1988 garantiu a indissociabilidade do ensino, da pesquisa e da extensão enquanto princípio a ser obedecido pelas universidades, mas sem atividades consistentes por parte da comunidade acadêmica em relação a Extensão, infelizmente a indissociabilidade permanecerá apenas na letra da Lei.

A Universidade Federal do Cariri, em seu site institucional , adota o conceito de extensão do Plano Nacional de Extensão, para o qual "A Extensão Universitária, sob o princípio constitucional da indissociabilidade entre ensino, pesquisa e extensão, é um processo interdisciplinar, educativo, cultural, científico e político que promove a interação transformadora entre Universidade e outros setores da sociedade". Diante do exposto, o problema a ser respondido é como o conceito de Extensão evoluiu e qual a sua relação com a democratização da universidade?

Este trabalho apresenta como o conceito de Extensão foi construído, apresentado o dinamismo que marca as transformações do conceito e das próprias ações de extensão, que hoje não se limitam mais a promover cursos de curta duração à comunidade interna e externa da universidade.

O objetivo do artigo é apresentar a evolução do conceito de Extensão Universitária, por meio da análise de sua construção através do tempo, apresentando as diversas formas do Fazer Extensionista, do seu surgimento, como oferta de cursos ou simples prestação de serviços, aos dias atuais, em que a Extensão assume protagonismo na universidade ao lado do Ensino e da Pesquisa. Para tanto, apresentará a 
discussão teórica sobre o tema e, por fim, como um projeto de extensão, realizado na Universidade Federal do Cariri, apreende em suas atividades o conceito de extensão e de seu público-alvo, podendo assim verificar a validade do conceito de Extensão, ora reivindicado pelas universidades e demandado pela sociedade brasileira.

\section{METODOLOGIA}

E sta pesquisa se caracteriza como uma pesquisa exploratória, uma vez que Gil (2008, p. 27) a aponta como aquela que busca principalmente "desenvolver, esclarecer e modificar conceitos e ideias, tendo em vista a formulação de problemas mais precisos ou hipóteses pesquisáveis para estudos posteriores". O estudo realizado neste trabalho é, ainda, de caráter qualitativo, pois "tem o ambiente natural como a fonte direta de dados e o pesquisador como instrumento fundamental" (FREITAS; JABBOUR, 2OII, p. II). A pesquisa realizar-se-á em duas fases: um estudo bibliográfico, por meio da revisão de literatura e o Estudo de caso, realizado em um dos projetos de extensão da Universidade Federal do Cariri.

O trabalho realizou uma revisão da literatura, abordando a extensão desde suas origens para montar seu histórico desde suas primeiras experiências aos dias atuais. A literatura sobre extensão universitária forneceu a gênese do conceito de extensão universitária e como em sua relação com os anseios sociais da comunidade, ele foi sendo modificado até chegar a forma como a atual extensão universitária brasileira está atuando para incluir a responsabilidade social e o desenvolvimento regional sustentável no retorno à sociedade. Para este trabalho utilizou-se principalmente de fontes digitais, disponíveis nos sítios eletrônicos, e de trabalhos publicados em periódicos, de forma que se buscou realizar uma revisão integrativa, que apresentasse, como o conceito de revisão foi formulado inicialmente e suas modificações posteriores.

Ainda como forma de verificar a maneira como a extensão se efetua no Cariri Cearense, a saber na Universidade Federal do Cariri (UFCA), o trabalho aborda um projeto de extensão, por meio de observação participante do autor, que integrou o mesmo no período de 2018 a 20I9. Foram utilizados também os relatórios sobre o programa enviados para o acompanhamento do mesmo pela Pró-Reitoria de Extensão da UFCA,

Através dessa atividade em campo, o trabalho identifica as reflexões que os participantes do projeto de extensão puderam formular, apresentando o Fazer Extensionista na UFCA.

\section{RESULTADOS E DISCUSSÃO}

É fato que a universidade tem várias contribuições a fazer para a sociedade brasileira. Mas o inverso também é verdadeiro, pois a sociedade também tem contribuições a fazer à universidade. Para que a construção de uma universidade democrática possa acontecer, a complexidade do mundo deve ser reconhecida e não excluída da universidade. Trazer a complexidade para dentro de seus muros, estimulando a diversidade, compreendê-la são formas de avançar para o modelo mais inclusivo, mais democrático de universidade (MORIN, 2OII).

As universidades brasileiras realizam uma série de atividades que são executadas sob o rótulo de Extensão, buscando principalmente dialogar com a sociedade. Essas atividades possuem diversos destinatários: grupos sociais populares e suas organizações; movimentos sociais; comunidades locais ou regionais; governos locais; o setor público; o setor privado (SANTOS, 2OIO). Afinal, "é o ensino superior o que tem uma das maiores responsabilidades na produção, sistematização e difusão do conhecimento, na pesquisa, na inovação tecnológica, na relação com a sociedade,

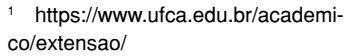


especialmente por meio da extensão" (BALDIJÃO; TEIXEIRA, 2OII, p. 42).

Ao relacionar-se com a comunidade externa, as reflexões, confrontos e transformações próprias da sociedade brasileira, são trazidas para o seio da universidade, já que esta é uma instituição social desta sociedade (SOUZA, 2OI3). Estabelecer esse relacionamento se faz necessário porque

[...] a produção de conhecimento não é mais exclusividade das universidades e sim de sua interação desta com a sociedade, seja pelas iniciativas públicas, como o financiamento para projetos de pesquisa e extensão, ou por intermédio de parcerias entre universidades e instituições de iniciativa privada (BERNARDES et al, 2OI4, p. 2I).

As práticas de extensão surgiram por volta de I9IO, como atividades acessórias aos cursos superiores. De acordo com Nogueira (2005), a extensão universitária teve início em I9II, na Universidade Popular, a antecessora da Universidade de São Paulo, aplicando o modelo de extensão, surgido nas universidades europeias ainda no século XIX, baseado na oferta de cursos àqueles que estavam fora da universidade. Esses cursos, não procuravam identificar os anseios e necessidades da população, pois eram pensados olhando apenas para a própria universidade, ou seja, a instituição continuava a falar para si mesma. Na década de $\mathrm{I} 92 \mathrm{O}$ foi a vez do modelo americano de extensão universitária ser praticado no Brasil. Algumas universidades passam a prestar serviços de assistência técnica a agricultores. São esses dois modelos de extensão, o da oferta de cursos e o da prestação de serviços que durante um bom tempo serão sinônimos de extensão nas universidades brasileiras. Era muito claro que as ações se baseavam em um viés assistencialista, com a proposição de soluções de curto e médio prazo, que partiam da universidade para a sociedade, sem discutir essas soluções, bem como as necessidades com a sociedade que buscavam atender. Fernandes et al. (20I2) explicam que esse modelo de extensão assistencialista, apenas impõe conhecimento à comunidade, impedindo que esta possa criar seu próprio conhecimento. Na verdade, a extensão para as universidades...

[...] até o final dos anos I950, apresenta-se, em geral, como um instrumento para difundir resultados da pesquisa nelas produzidas e reforçar o ensino elitista nelas ministrado. Os cursos de extensão realizados beneficiavam uma clientela egressa ou frequentadora de seus cursos regulares e que, quase sempre, era a mesma que se interessava pelos resultados da pesquisa. (NOGUEIRA, 2005, p. IOI)

Até os anos I96o, a atividade básica das universidades era o ensino (HUNGER et al. , 2OI4). A industrialização e a urbanização do país demandavam novas atuações por parte da universidade, o que a levaria a tomar a postura, segundo Nogueira $(2005)$, de articular o ensino e a pesquisa em um processo educativo, científico e cultural. As instituições de ensino superior deixavam de ser apenas formadoras de quadros para elite e passaram a atuar mais no processo de desenvolvimento brasileiro, conciliando conhecimento produzido nestas instituições com o este novo quadro de urbanização e industrialização (CHALUB et al. , 20I2).

Na década de I980, com a ascensão de uma concepção de universidade enquanto instrumento de transformação social, a extensão passa a ser vista como a ferramenta por excelência dessa transformação.

As transformações da sociedade brasileira nos anos da década de ı980, como a ascensão dos movimentos sociais e a redemocratização, pressionaram por mudanças profundas em todas as instituições do país. Nesse contexto, a Universidade não poderia mais esperar que sua legitimidade fosse assegurada apenas pela formação de uma elite privilegiada e da produção de um conhecimento também socialmente privilegiado (SANTOS, 2OIO). Concebida para educar as elites, a Universidade foi chamada a se reinventar. Ela, agora precisa dialogar com outros públicos, que histo- 
ricamente foram excluídos do ensino superior.

Para cumprir essa tarefa, a Universidade necessitava de uma nova concepção de extensão. A extensão que se realizava de forma assistencialista e sem procurar dar respostas aos questionamentos que eram feitos pela sociedade à universidade e até mesmo aos questionamentos que a universidade fazia a si mesma precisava ser superada (VARGAS, 20I3).

A universidade pode vir a ser uma propulsora de transformação social, uma vez que possui a capacidade, por meio de suas atividades, de impulsionar melhorias na qualidade de vida da sociedade (FERNANDES et al. , 2OI2). As atividades de extensão podem ser as ferramentas para responder as demandas da comunidade do entorno da universidade, fazendo desta uma instituição comprometida e atuante para com a sociedade (BERNARDES et al. , 2OI4), desde que, como diz Silva (20I6), a Extensão deixe de operar como mera difusora do conhecimento produzido e passe a fazer com que a universidade se insira na realidade social e política da nação. Dessa forma

\footnotetext{
En este sentido, las políticas de extensión no pueden ser estáticas. Las acciones que se implementen, em la medida en que estén vinculadas a las necessidades del entorno, no se agotan, se enriquecen y se retroalimentan. También es necesario que se integren hacia um fin común y que sean asumidas por toda la comunidade universitaria, em la búsqueda de generar mayor compromiso y una mayor interacción e impacto em el entorno de la universidad. (MORALES RUBIANO; ORTIZ-RIAGA, 2OII, p. 36I).
}

Por isso os conceitos e definições para a extensão, apresentadas na literatura sobre o tema são tantos e tão diversos. O I Encontro Nacional de Pró-reitores de Extensão, realizado em I987, definiu a extensão como "o processo educativo, cultural e científico que articula o Ensino e a Pesquisa de forma indissociável e viabiliza a relação transformadora entre universidade e sociedade" (NOGUEIRA, 2005, p. 84).

Esta formulação considerou a indissociabilidade entre extensão, ensino e pesquisa, bem como uma perspectiva transformadora na relação entre a sociedade e a universidade por meio da educação, da cultura e da ciência. Em outras palavras "colocar a produção do conhecimento universitário em contato com a sociedade na qual se insere, para perceber as demandas da mesma e propor soluções a essas demandas, foi seu núcleo central” (SILVA, 20I6, p. 37).

Essa interação transformadora com a sociedade, somada a indissociabilidade com o Ensino e a Pesquisa, que a constituição de I988 iria consagrar, apontam para a extensão como o ponto de ligação entre a universidade e a sociedade.

O relacionamento entre universidade e comunidade externa, que já vinha sendo feito pela extensão, seria ampliado e transformado, assumindo uma lógica de diálogo, para que, segundo Alves (2OI4), o conhecimento pudesse ser fruto das trocas entre os saberes e buscas comuns da universidade e da sociedade. Os saberes circulariam entre ambas, transformando o conhecimento produzido pela universidade. Este beneficiaria a sociedade pela aproximação entre os conhecimentos científicos e tecnológicos e a realidade social do entorno da academia.

É por meio da compreensão de que a Universidade se insere em um território que apresenta problemas sociais diversos de outros, que o tripé formado por Ensino, Pesquisa e Extensão pode atuar sobre essa realidade e responder aos problemas que o diálogo com os diversos segmentos da sociedade lhe permitirão identificar (SILVA, 20I6, p. 38).

Em outras palavras, a Universidade observar a dinâmica social do seu entorno para que suas pesquisas possam dar as respostas que aos problemas reais da socie- 
dade, uma vez que,

O debate atual acerca da responsabilidade social universitária tem ganhado uma posição de destaque e uma dimensão cada vez mais evidente, na qual a extensão tem sido apontada como um significativo mecanismo de aproximação da universidade com a sociedade. Em se tratando da responsabilidade social das instituições de ensino superior, há de se levar em conta o perfil e a missão educacional da instituição, bem como seu posicionamento frente aos problemas sociais de seu tempo. (RIBEIRO, 2OII, pg. 82)

A Universidade não pode esperar cumprir com sua responsabilidade social, apenas com a oferta de educação por educação, faz-se necessário que ela recorra às ações de extensão (NOGUEIRA, 2005). Mas ações de extensão que produzam conhecimento novo, em interação com a sociedade, que possa contribuir para superar a desigualdade e a exclusão social, no qual tanto a formação do aluno, quanto a promoção do desenvolvimento regional, possam ser realizadas (LACERDA, 2OI4).

Alves (2OI4) considera que a universidade se democratiza ao promover a aproximação de saberes, transformando esta, a qual é uma instituição que historicamente evita o encontro regular com a sociedade, principalmente os setores mais vulneráveis da sociedade brasileira, que são historicamente excluídos do acesso ao ensino superior. A busca por essa nova relação, acaba por desnudar o conflito entre duas correntes antagônicas da universidade.

[...] aquela que almeja um ensino monodirecional no qual prevalece a ideia de conhecer por conhecer, a excelência da instrução em detrimento das necessidades da sociedade, e a que prioriza a aplicação dos conhecimentos produzidos nos diversos contextos sociais, a troca de saberes e a justaposição entre a sociedade e a universidade... (CHALOUB et al., 2OI2, p. II4)

Ambas as correntes estão à procura de legitimar-se enquanto direção das instituições, para que dessa forma possam determinar qual o caráter funcional das instituições de ensino superior. É um conflito claro entre os objetivos da educação pública gratuita e os da educação mercantilizada. Por conta desses conflitos, diversas contradições podem ser observadas na universidade e em suas atividades de extensão, dentre as quais podem ser ressaltadas:

A contradição entre a produção da cultura utilitarista que atende a formação das elites e a produção de conhecimentos para a transformação social; a contradição entre a hierarquização dos saberes por meio das restrições de acesso e as exigências de democratização das oportunidades; a contradição entre o modelo de avaliação universitária centrada na produtividade e a autonomia universitária. (CASTRO et al., 20I4, p. 64)

Vale ressaltar que cada uma das correntes expostas acima tem, por sua vez, a própria concepção de extensão. Isso reforça o caráter a que esse trabalho já aludiu de que a extensão é um conceito em construção e que, portanto, permanece em disputa.

Atualmente, a atuação dos movimentos populares somada a maior criticidade do movimento estudantil tem contribuído para uma maior abertura social da universidade brasileira. Este é um movimento de inserção social que vai além das práticas extensionistas, 
e ensinar, pois novos olhares comprometidos com o território e sua gente alimentariam a prática pedagógica sobre bases curriculares e a investigação (ALVES, 20I4, p. I4).

Dessa forma, o eixo pedagógico clássico, baseado na relação professor/ aluno se desloca para um novo eixo, protagonizado pela relação aluno/comunidade (CHALUB et al., 20I2). Nessa nova pedagogia o professor exerceria a orientação, uma tutoria, de uma rede de educadores. Alunos e professores seriam sujeitos do aprendizado, fazendo da extensão uma forma de democratização do saber acadêmico, reelaborando-o com a comunidade, trabalhando o saber reelaborado na universidade, por meio de novas pesquisas, para que neste ciclo de trocas seja construído um conhecimento capaz de contribuir na transformação social (VARGAS, 2OI3).

Com isso, até mesmo a sala de aula seria transformada. A indissociabilidade entre Ensino, Pesquisa e Extensão, estaria sendo realizada na prática. Como expõe Abranches (2OI4, p. 5O),

A pesquisa está presente nas ações de extensão para permitir conhecer, analisar e intervir na realidade, pois a esta garante a oxigenação do ensino e da extensão a partir dos questionamentos sobre a realidade vivenciada. O ensino deve se articular com a pesquisa e a extensão para não se reduzir a reprodução de conteúdos, e a extensão precisa se articular à pesquisa e ensino para não se reduzir ao ativismo.

Nesse sentido "fazer extensão é ser educador comunicante" (ALVES, 2OI4, p. I9), ou seja, realizar a articulação entre as partes constituinte do tripé Ensino-Pesquisa-Extensão, somando as contribuições de cada elemento dentro da universidade, bem como as contribuições externas, buscando a constante reelaboração do conhecimento. Para Alves (2OI4), a extensão articula os encontros entre as classes populares e a universidade, valorizando saberes que eram negados, propiciando mudanças que resultam em melhorias na vida, tanto dos indivíduos, quanto das coletividades. Para que possa atuar dessa forma, a extensão precisa sair da passividade e assumir-se enquanto estratégica para a sociedade e para universidade, levando a uma "universidade mais comprometida e atuante com seu entorno” (BERNARDES et al, 2OI4, p. 2I).

Mas como a extensão pode ser estratégica? Como a investida da extensão no campo social pode ser transformadora? Para isso, Abranches (2OI4) acredita que são necessárias uma dimensão técnica, uma crítica e uma ética. Técnica por exigir competências para o planejar, implementar e avaliar as ações propostas. Uma dimensão Crítica na medida em que a todo momento questiona o sentido do agir. E por fim uma dimensão Ética para que possa avaliar a sua efetividade em termos das transformações realizadas de forma positiva na comunidade. Em outras palavras na forma como deu respostas aos anseios do público-alvo de suas ações.

A atual concepção de extensão não deixa de realizar a prestação de serviços. Ela é feita abandonando o anterior marco assistencialista. A prestação de serviços assume um caráter de assessoria, compondo o processo criativo, devendo ser

[...]de cunho emancipatório e não assistencialista, seja remunerada ou não. Alerta-se para o risco de a prestação de serviços vir a constituir-se um fim em si mesma, servindo apenas como instrumento para captação de recursos, tornando-se precedente para o Estado restringir suas responsabilidades para com o ensino superior público. (NOGUEIRA, 2005, p. II5)

A Extensão, tal como está exposta na concepção acima, exige, por sua vez, uma concepção de universidade, em que a educação seja vista como direito e não como um privilégio ou um simples serviço. A efetivação dessa concepção somente é possível por meio da democratização do Estado, a qual levará a democratização da 
universidade (CHAUÍ, 2OO3), como aponta Santos (2OIO, p. II3) “a universidade é um bem público intimamente ligado ao projeto de país". O que implica na necessidade de oposição à agenda neoliberal que por hora avança na reformulação de diversas políticas públicas brasileiras, as de Ensino Superior entre elas.

A extensão universitária insere professores, técnicos e alunos na realidade do território extramuros da universidade. Uma inserção que deve ser permanente, uma vez que tira a universidade do isolamento e lhe permite a troca de experiências e vivências, assim como revisar constantemente seus valores.

Como é possível observar a extensão longe de ser um conceito estático, permanece em constante movimento não só para responder as demandas da sociedade brasileira, como também para provocar essas demandas. É um processo que retroalimenta também as mudanças na universidade, fazendo com que a universidade, a sociedade e a extensão realizem trocas e avanços constantes no decorrer da sua história. Foi essa concepção que levou a constituição do Projeto Viés Cariri, elaborado como um espaço de discussão dos desafios do semiárido na Universidade, não apenas com servidores e estudantes, mas com a comunidade que vive e trabalha no território.

O programa iniciou suas atividades em 2OI7, buscando a constituição de um amplo espaço de discussão dos problemas do território do Cariri, para que as soluções para os mesmos fossem pensadas junto com sua comunidade. A proposta era de abandonar a repetição de conceitos, e passar a reelaborá-los, por meio de um amplo debate sobre a economia, questionando os parâmetros que passavam a conduzir as políticas públicas a partir de 20I6, a saber o neoliberalismo e as medidas de austeridade como o Teto de Gastos. Dessa forma apresentando as nuances diversas de um debate que a mídia e outros formadores de opinião insistiam em simplificar.

Em 20I8, o Viés foi renovado e reforçou a natureza multidisciplinar do projeto, ao receber a adesão de profissionais das mais diversas áreas de pesquisa $\mathrm{e}$ atuação na UFCA, como economistas, administradores, pedagogos, historiadores e psicólogos, além de alunos dos mais diversos cursos da universidade.

O Projeto buscou dialogar com a comunidade extramuros da universidade, mostrando que a desigualdade e a escassez de oportunidades não são naturais, mas sim uma construção política e social e como tal pode e deve ser transformada, sendo que os saberes, experiências e vivências da comunidade seriam valorizadas na efetivação da transformação da realidade do território.

Por isso o Viés Cariri utilizou manifestações artísticas e culturais, com jovens da periferia das cidades de Juazeiro do Norte e Crato, e a realização de eventos como debates palestras e os chamados diálogos sobre Economia e sociedade. Nesses diálogos, a discussão de textos clássicos de economia subsidiava os debates das questões econômicas, sociais e culturais que interferem na universidade e no território como um todo.

Além das atividades do projeto, ao final de 20I8, realizou-se uma atividade de formação entre os participantes do projeto, um momento de aprendizagem e de trocas de experiências, bem como de refletir sobre a atuação do projeto. Esta atividade contou com ro (dez) participantes, entre docentes, discentes e técnicos.

A formação ressaltou a importância da interdisciplinaridade e da transdisciplinaridade para a produção do conhecimento. Durante os debates algumas das falas chegaram a comparar a produção do conhecimento, realizada no projeto, com as peças de Lego, que apesar de possuírem um manual indicando como montar, podem ser combinadas de forma diferentes e originar novos brinquedos, novas oportunidades, tal como a combinação dos saberes popular e acadêmico. 
É uma reflexão que reconhece que "o conhecimento das informações ou dos dados isolados é insuficiente" (MORIN, 2OII, p. 34). As atividades de extensão permitiram que a combinação de conhecimentos diversos construíssem algo novo, a partir do preexistente.

Esse momento de formação demonstrou a necessidade de ampliar o contato da academia com os saberes populares, reinventando a cultura acadêmica para que a integração de saberes e a natural diversidade cultural se reflita na produção universitária. Ao fim, entende-se que

O impacto das ações de extensão, desenvolvidas pelos participantes, demonstram a vitalidade que o Fazer Extensionista pode atingir, enquanto se mantiver como proposta aberta, não apenas para seus integrantes, mas para o público interno e externo da universidade (SILVA et al, 2019, p. 34).

A extensão, tal qual a universidade, vem, desde a sua origem, assumindo diversos papéis e funções: de início simples atividades acessórias, depois assumindo um caráter assistencialista de prestação de serviços e oferta de cursos, até a concepção mais recente, onde a extensão busca produzir conhecimento para a transformação social, não vendo a sociedade como simples fator passivo nesta empreitada, mas como agente ativo, com saberes, viveres e experiências válidas. Esta nova postura é encampada num momento em que a própria universidade se abre a grupos que durante muito tempo estiverem distantes dela. A redemocratização do país na década de I980 provocou alterações sensíveis na sociedade brasileira, na qual as classes populares passaram a reivindicar mais direitos e a mudanças nas relações sociais que apontassem uma maior participação popular. Movimentos populares, dentre eles o movimento estudantil, se organizam para lutar por terra, moradia, respeito à diversidade e diversas outras bandeiras que haviam sido silenciadas pela ditadura. $\mathrm{O}$ modelo de desenvolvimento não poderia mais ser o modelo autoritário, mas um modelo participativo. E o canal de contato da Universidade com essas reivindicações, para não só trazer essas demandas para o ambiente acadêmico, mas para tirar a própria academia de seu isolamento e torná-la uma ferramenta da democratização da sociedade brasileira foi a extensão.

Por isso nos fins dos anos I98o ela foi chamada ao protagonismo, alçada junto com o ensino e a pesquisa, como princípios básicos da universidade, com a indissociabilidade deste tripé estabelecida pela constituição de I988. Mas ainda existe um longo caminho para que a letra da lei se torne mais efetiva. Porque a cultura e o saber popular têm contribuições a fazer a universidade e não só como objeto de pesquisa, mas como conhecimento válido, entendendo a complexidade do mundo e invés de excluir essa complexidade, compreendê-la, para avançar na de uma universidade democrática (MORIN, 2OII).

Ainda é preciso um compromisso efetivo dos gestores e da comunidade universitária para que a extensão possa atingir todo o seu potencial na construção da democracia na Universidade brasileira.

\section{CONSIDERAÇÕES FINAIS}

O presente trabalho é um esforço para capturar um esboço da história do conceito de extensão, o que acaba por trazer elementos da história da própria extensão. Uma tarefa gigantesca, haja vista o tamanho do tema, com um recorte temporal que se inicia no início do século XX e se estende aos dias atuais.

Quando o Plano Nacional de Extensão afirma que Extensão Universitária “sob o princípio constitucional da indissociabilidade entre ensino, pesquisa e extensão, é um processo interdisciplinar, educativo, cultural, científico e político que promove a interação transformadora entre Universidade e outros setores da sociedade”, está 
reafirmando um conceito construído historicamente, onde se reconhece não apenas as origens da prática extensionista, mas da própria universidade, pois ambas se complementam e se transformam. A sociedade que agora pressiona a universidade por maior democratização, por maior acesso, pode ser contemplada pelas atividades que $o$ atual conceito de extensão evoca.

É importante observar que a Extensão vem sendo cada vez mais reconhecida como vital para a universidade, em um movimento estimulado tanto pelas comunidades acadêmicas, ao entenderem a importância do relacionamento com a comunidade extramuros, que é realizada pela Extensão, quanto por medidas legais, como a creditação da extensão nos cursos de graduação. Há que se considerar ainda as demandas da própria sociedade para a Universidade, uma vez que esta pode assumir uma série de papéis no que diz respeito ao desenvolvimento regional, diminuição das desigualdades, difusão de tecnologias, entre outros.

Ao considerar o atual conceito de extensão, não se deseja mais apenas fornecer o que deseja a sociedade, mas trazê-la para dentro da universidade, com suas vivências, saberes e experiências, e assim produzir um conhecimento novo, que seja desde o princípio validado pelas trocas entre saber acadêmico e saberes populares. Uma tessitura que considera a complexidade e a diversidade social e cultural dos brasileiros. O Viés Cariri é um dos exemplos de como o contato entre universidade e sociedade não só é realizado, como transformado, a partir do momento em que se assume a validade do novo fazer extensionista.

Desse modo esta pesquisa é um ponto de partida para diversos outros estudos sobre a extensão, de forma a compreender sua historicidade, levando a reflexão que o atual conceito de extensão é fruto de uma constante evolução e como tal é passível de novas modificações. Estando a comunidade universitária atenta às necessidades sociais da sociedade brasileira, o diálogo por meio da extensão permitirá que a universidade se aproxime ainda mais das camadas mais vulneráveis da população, permitindo a democratização não só do acesso, mas da gestão e dos saberes produzidos na universidade.

Afinal, como o texto aponta em diversos momentos, é preciso democratizar não apenas o conhecimento, mas a própria universidade, fazendo com que a extensão possa ser o caminho para questionar um modelo que ainda se faz excludente, diante da formação histórica do Brasil, permeada de desigualdades, sejam econômicas, raciais ou de gênero.

\section{REFERÊNCIAS}

ABRANCHES, Mônica. Política nacional de extensão universitária - 2OI2: identidade e diretriz para a prática extensionista no ensino superior brasileiro. In: Extensão universitária: conceitos, propostas e provocações. João Gremmelmaier Candido e Luciane Duarte da Silva (org). São Bernardo do Campo: Universidade Metodista de São Paulo, 2OI4.

ALVES, Luiz Roberto. Estender-se comunicando: o caminho para a universidade que forma sujeitos (uma leitura freiriana). In: Extensão universitária: conceitos, propostas e provocações. João Gremmelmaier Candido e Luciane Duarte da Silva (org). São Bernardo do Campo: Universidade Metodista de São Paulo, 2OI4.

BALDIJÃO, Carlos Eduardo; TEIXEIRA, Zuleide Araújo. A educação no governo Lula. São Paulo: Editora Fundação Perseu Abramo, 2OII.

BERNARDES, Marco Aurelio; PELARIN, André Luiz; SILVA, Luciane Duarte da. Indicadores e parâmetros para a estrutura da extensão universitária em uma IES. In: Extensão universitária: conceitos, propostas e provocações. João Gremmelmaier 
Candido e Luciane Duarte da Silva (org). São Bernardo do Campo: Universidade Metodista de São Paulo, 2OI4.

BRASIL. Lei nº 9·394, de 20 de dezembro de 1996.

CASTRO, Luciana Maria Cerqueira; MAIOR, Rossana Serrano Souto; MEIRELLES, Fernando Setembrino Cruz; SANTOS, Sônia Regina Mendes dos. Avaliar a extensão: uma construção possível? In: Extensão universitária: conceitos, propostas e provocações. João Gremmelmaier Candido e Luciane Duarte da Silva (org). São Bernardo do Campo: Universidade Metodista de São Paulo, 20I4.

CHALUB, Leila; FRATE, Claudio Albuquerque; VICENTIM, Fabiana Moreira. Inserção social e universidades brasileiras: as melhores práticas. In: As novas dimensões da universidade: interdisciplinaridade, sustentabilidade e inserção social. Elimar Pinheiro do Nascimento e Alfredo Pena-Veja (orgs.). Rio de Janeiro: Garamond, $2 \mathrm{OI2}$

CHAUI, Marilena. A universidade pública sob nova perspectiva. Rev. Bras. Educ., Rio de Janeiro, n. 24, p. 5-I5, dez. 2003.

FERNANDES, Marcelo Costa; SILVA, Lucilane Ma Sales da; MACHADO, Ana Larissa Gomes; MOREIRA, Thereza Ma Magalhães. Universidade e Extensão Universitária: a visão dos moradores das comunidades circunvizinhas. Educação em Revista. Belo Horizonte, v.28, n.04, p.I69-I94, dez. 2012.

FREITAS, Wesley R. S.; JABBOUR, Charbel J. C. Utilizando estudo de caso(s) como estratégia de pesquisa qualitativa: boas práticas e sugestões. Estudo \& Debate, Lajeado, v. I8, n. 2, p. 7-22, 20II. Disponível em: <https://edisciplinas.usp. br/pluginfile.php/2I48238/mod_resource/content/I/Protocolo\%2Ode\%2Oestudo\%2ode\%2ocaso.pdf $>$. Acesso em: 29 jan. 2020

GIL, Antonio Carlos. Métodos e técnicas de pesquisa social. São Paulo: Atlas, 2008.

HUNGER, Dagmar; NOZAKI, Joice Mayumi; PEREIRA, Juliana Martins; ROSSI, Fernanda. O dilema da extensão universitária. In: Educação em Revista. Belo Horizonte, v.3O, n.o3, p.335-354, julho-setembro 2OI4.

LACERDA, Wlesca Portella de; VIEIRA, Edson Trajano. A Extensão Universitária e o desenvolvimento regional. In: III Congresso Internacional de ciência, tecnologia e desenvolvimento, Taubaté, 2OI4. Anais. Taubaté: 2OI4.

MORIN, Edgar. Os setes saberes necessários à educação do futuro. Trad. Catarina Eleonora F. da Silva e Jeanne Sawaya. São Paulo: Cortez; Brasília/DF: UNESCO, $2 \mathrm{OII}$.

MORALES-RUBIANO, María Eugenia; ORTIZ-RIAGA, María Carolina. La extensión universitária en América Latina: concepciones y tendencias. Educ.educ., Chia , v. I4, n.2, Ago. 20II. Disponível em <http://www.scielo.org.co/scielo.

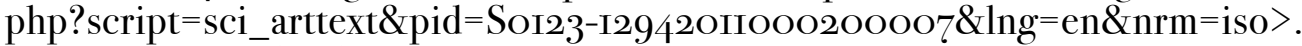
Acessado em 29/o7/202O.

NOGUEIRA, Maria das Dores Pimentel. Políticas de Extensão Universitária Brasileira. Belo Horizonte: Editora UFMG, 2005.

RIBEIRO, Raimunda Maria da Cunha. A Extensão Universitária como indicativo de responsabilidade social. Revista Diálogos: Pesquisa em Extensão Universitária. Brasília, v.I5, n.I, pg. 8I-88, jul 201 I. 
SAKAMOTO, Cleusa Kazue; SILVEIRA, Isabel Orestes. Como fazer projetos de iniciação científica. São Paulo: Paulus, 2OI4.

SANTOS, Boaventura de Sousa. A Universidade no século XXI: para uma reforma democrática e emancipatória da universidade. São Paulo: Cortez, 2010.

SILVA, Wagner Pires da. As ações de extensão na construção de uma universidade sertaneja. 20I6. I35f. Dissertação (Mestrado) - Universidade Federal do Ceará, Fortaleza, 20I6.

SILVA, Wagner Pires da; SOUZA, Ana Carmita Bezerra; BARBOSA, Erlene Pereira; MACIEL, Paulo Henrique Freitas. Entendendo a desigualdade, como forma de combatê-la, por meio das ações extensionistas do Viés Cariri. Revista RAÍZES E RUMOS, Rio de Janeiro, v. 7, p. 31-36, 20I9.

SILVEIRA, I. S. Observação Participante: um olhar encantador. Revista Lato \& Sensu. Belém, n I, v. 4, p. 3-5. out. 2003

SOUZA, Lenilza Alves Pereira. Extensão Universitária: institucionalidade e compromisso social. 20I3. Io6f. Dissertação (Mestrado) - Pontifícia Universidade Católica de Goiás, Goiânia, 2OI3.

VARGAS, Daniella Aparecida Molina. A concepção e a prática da extensão universitária nas instituições de ensino superior da região do Médio Iguaçu. 2OI3. IIgf. Dissertação (Mestrado) - Universidade do Contestado, Canoinhas/SC, 2OI3. 